\title{
New Installions
}

\section{MULTI-FLEXIBLE LANGUAGE LABORATORY}

\section{by Francis $H$. Yonker}

Inflationary pressures have increased educational costs. Administrators, meanwhile, are forced to reduce budgets while John $\mathbf{Q}$. Fublic criticizes the high cost of education and wants a reduction in taxes for schools. This vicious circle is producing problems in every city in the country and much effort is being expended in studies for reducing costs and making physical plants more efficient.

Bergen Community College kept this in mind while designing and completing a new educational complex. A language laboratory was to be installed, but a vendor could not be found to meet the space utilization and efficiency requirements needed for a metropolitan community. The physical plant is utilized to a maximum by scheduling classes 14 hours per day. Every student at the college is a commuter and his time is precious; therefore, delays caused by poor scheduling and room utilization had to be eliminated to allow each student to get the most educational value per commuter trip through 100 percent seat capacity utilization.

Language labs of numerous manufacturers were inspected and studied at plants, convention exhibits and in schools. None of the existing designs met the requirements for simplicity, efficiency and 100 percent ultilization. Too often we heard the complaint that a teacher was in the lab with eight students and that thirty-two seats were empty and couldn't be used. Even with thirty-two students and only eight empty carrels, it often happened that someone was discouraged by not being able to enter the lab and use the empty seats.

An overall view of the new classroom arrangement is shown in figure 1.

(a) Seventy carrels are divided into sections of thirty-five oddand thirty-five even-numbered carrels which are separated by two supporting columns.

(b) Six identical large-size carrels for instructors are located across the front of the room.

(c) Behind the instructor carrels are located the seventy student tape recorders and the programming equipment.

All tape decks are standard 7-inch reel-to-reel type. These machines were specified because of their proven durability, high frequency response, reduced cross talk between channels or tracks and 
especially because sandwich tape could be loaded on the seventy decks and not be removed until worn out. All decks are programmed daily. Decks are isolated from students to eliminate breakage and other problems which occur when inexperienced personnel operate such mechanisms. Efficient maintenance and operation of the decks is accomplished by having all decks centrally located at the front of the room with the other switching and programming equipment.

A qualified technician programs the decks utilizing a computer print-out sheet which shows each deck's use as assigned to a particular student on registration day. Each lecture and lab period is specified by day, hour, room and seat or carrel number. To eliminate student cuts attendance is taken by a clerk. Each student must use only the carrel assigned to him because it is programmed for his class material.

Any student carrel or instructor carrel not in use is available immediately. Lectures can be explained and made more interesting by immediately taking the students to the laboratory to occupy empty carrels while the instructor plays either a reel tape, a cassette tape or a record. The instructor may also communicate directly with his students from his carrel without confusion because the switches for these students are illuminated in green on his control panel.

The six instructor carrels are identical except for position, isolation or view of the classroom (Figure 2). However, the instructor's carrel is much wider than the student's carrel. Each instructor position has seventy student switches (one for each carrel). Normally the switches corresponding to student positions are illuminated green. However, when a switch is flipped upward to the "ON" position, it turns yellow. In this switch position, the instructor may speak to the student. Another control switch allows three functions: all-call, groups, or monitoring.

The instructor's position is simplified in order to present the least confusion to the untrained. Only intercommunication and monitoring is performed. All other programming, mechanical control, and switching functions are removed to relieve the teacher of distraction. The technician presents all necessary controls for the programmed day. The clerk handles spur-of-the-moment requests when the teacher rushes in unexpectedly to reinforce part of his "just-finished" lecture.

As previously mentioned, the seventy student carrels are identical but are a little narrower than the instructor's carrel (Figure 3). The student has complete control of his tape machine by remote control. The tape machine was eliminated from the student's carrel area for two reasons. First, students tend to misunderstand many of the mechanical manipulations required of reel or cassette machines. Even when the machines are locked beneath the top desk surface, students 
New Installations
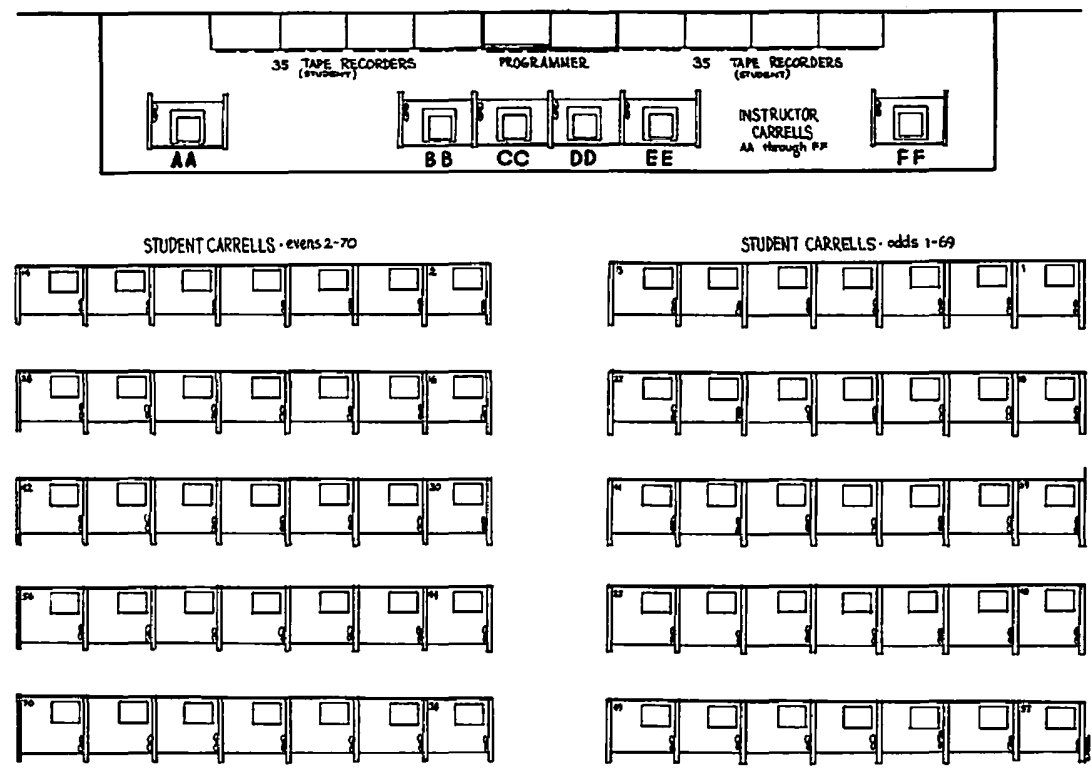

FIGURE I-OVERALL VIEW

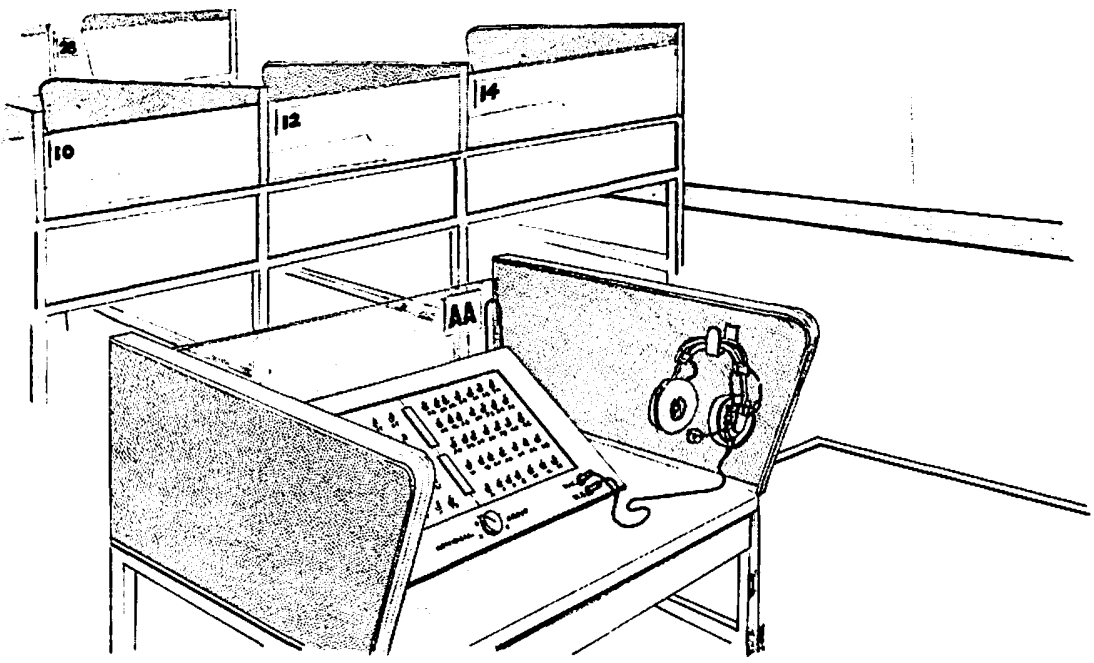

FIGURE 2- INSTRUCTOR'S CARREL 


\section{New Installations}

try to pry into them or to insert papers or paper clips into the area. Second, preventive maintenance and breakdown are easier to perform at one central location. The student has an audio-active-compare tape mechanism. The top of the two-track tape contains the master lesson and cannot be erased. The bottom half is blank and is available for the student's response or remarks. It is erasable and can be used over and over. The student can see by the tape Capacity Meter located in his booth the quantity of tape used during his participation. The tape is anchored to the reels and is controlled by photo cell-sensitive tape leaders which cause the tape to rewind to the beginning and reset for rerun. The normal control buttons, reverse, fast forward, play and record, are accompanied by a review button which allows the student to repeat a word or phrase by simply pushing it. The stop-rewind-stopplay functions are all combined for ease of operation. The volume control and dual headset outlets complete the remote control panel.

The programming module (Figure 4) consists of three main sections: (1) the master tape program players, (2) the dubbing-switching panel and (3) the instructor's lighting-switching panel. The six reel tape players allow the dubbing of eight programs onto the seventy student recorders simultaneously. Depending on the master tape speed, the recording-dubbing time can be $1 / 2$ real time by setting the capstan speed for 2:1 ratio. A special control panel allows monitoring

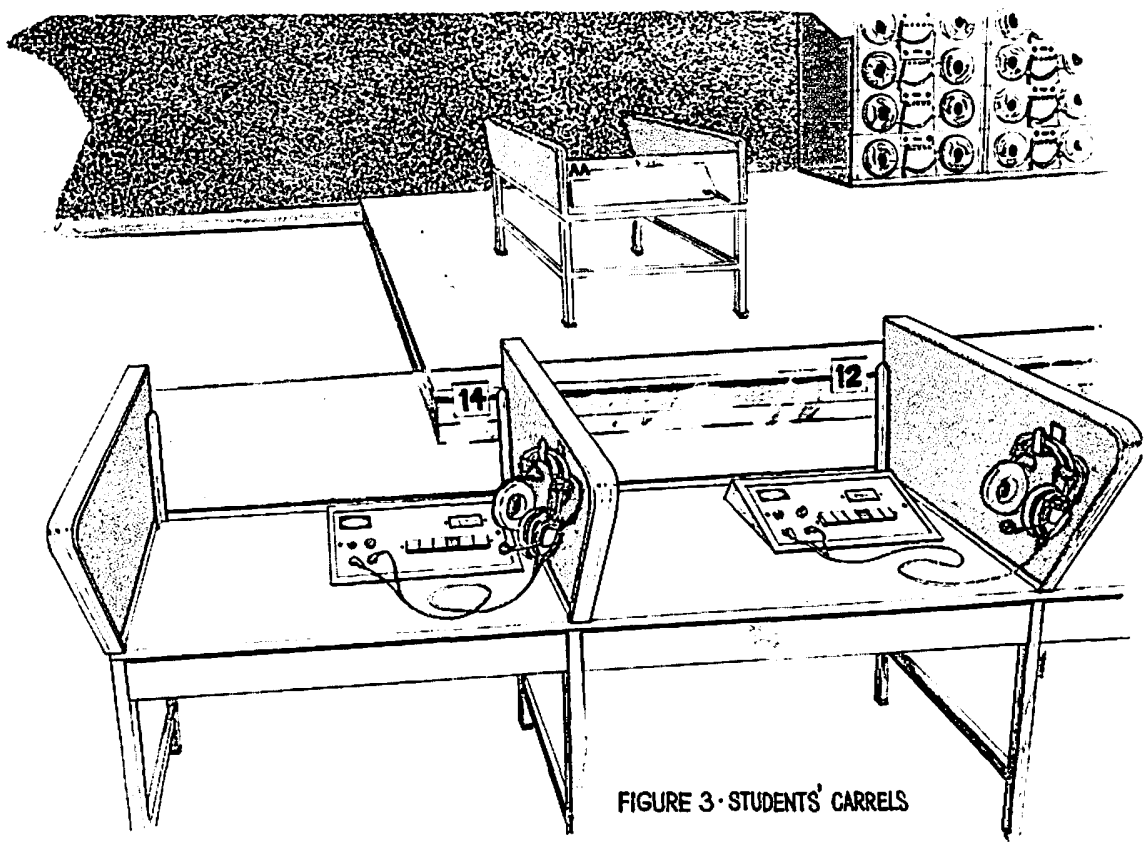


of the VU level and simultaneous switching "on" of groups of machines as desired. Master programs of different duration can be controlled separately. If desired, all of the master program players can be used as a real-time direct source of instruction to a specially selected group of students not desiring use of their own remote controlled machine.

All of the master program sources are switched to the different student recorders by the dubbing-switching panel. For example, student number 70 (Figure 5) has a knob on this panel that can be switched to Master Program number 1 (P1) or P2, P3, P4, P5, P6, P7, or P8. All student knobs are present and then all programs are dubbed simultaneously at a speed twice normal (time saving-one half). When all dubbing is complete, the student dubbing controls are set to "program" position to allow student study and participation at their own pace on their own tape.

The instructor's switch lightirg panel controls which student carrel switches shall be illuminated on the instructor's control panel. For example, if knob 42 (Figure 6) is set to position "AA", then at instructor "AA" carrel, switch 42 will be bright green color and will turn yellow when in the "ON" position. Any combination of students can be under control of any of the six instructors. This combination can be changed at any time to another instructor having any master program at his source. It is possible for any instructor to disregard his control panel switch lights and communicate across the seventy student carrels with individuals or groups. The VU meter panel allows monitoring of program level, remote local control of seventy student tape recorders and simultaneous starting and stopping of all tape mechanisms. Dubbings can be made while the student participates. That is, a master tape can be recorded on the student's machine while the student participates, but repeats must be delayed until the recording is copied. This emergency method could be used during a class period if the power had failed during pre-class programming.

The expense of this type of language laboratory was equal in cost to all other labs we inspected which have individual student recorders and one standard instructor console.

Expansion of the system is a simple task. Additional carrels in an adjoining room can be wired into student recorders that are interconnected with dubbing and switching panels. The same program sources can be used for dubbing ore as direct student programs. Efficiency in utilization of the facilities is the key feature of this type of language laboratory. Busy, time-pressed students can get their studying done on schedule and can utilize unused carrels for that spur-ofthe-moment urge to do more work. Instructors are not denied use of 
隹

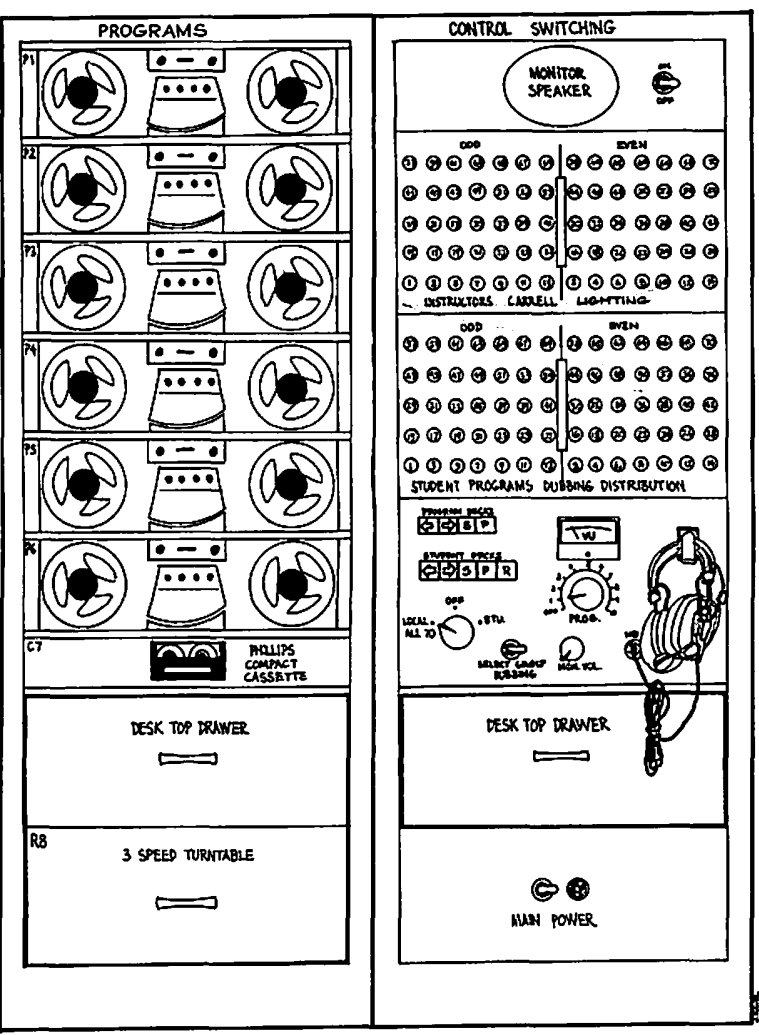

FIGURE 4- PROGRAM DUBBING OISTRIBUTION MODULE

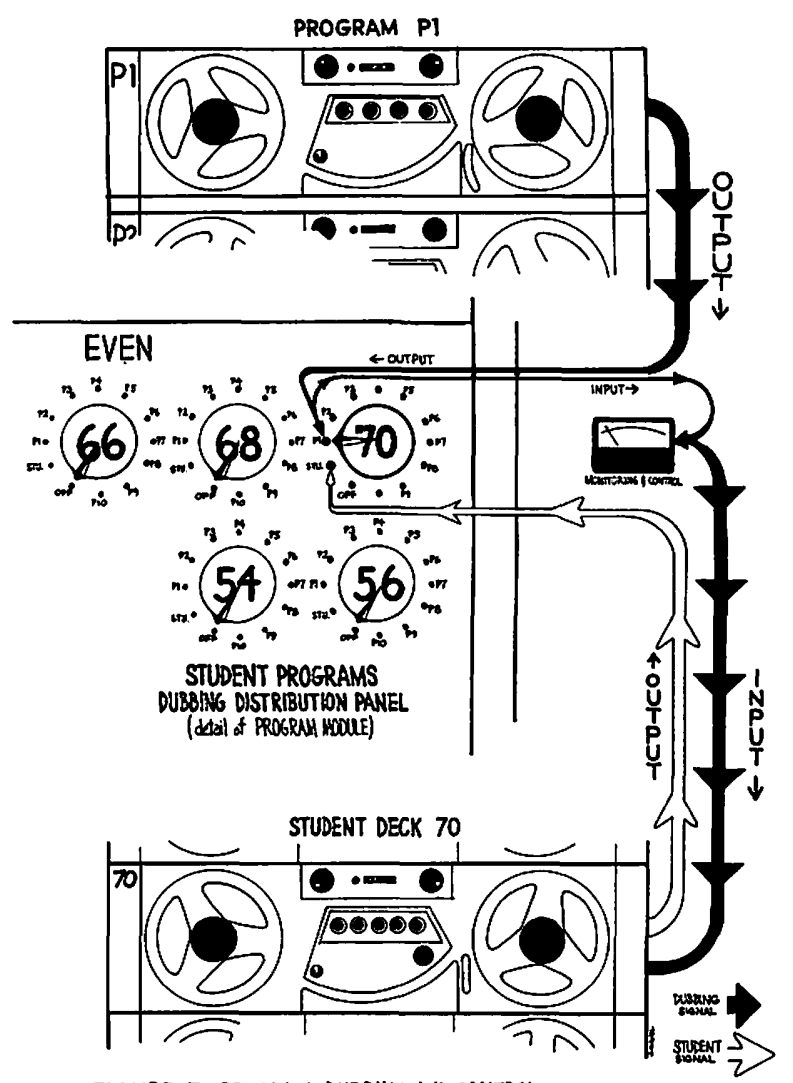

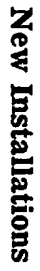


the lab because of conflicting schedules. Until every carrel in the lab is filled, someone can use the facility for study and instruction.

The exchange of ideas of theory, practice and experience between educator (Peter A. Helff, Associate Professor of the Library Learning Resources Center of Bergen Community College) and a Professional Engineer (Francis H. Yonker, Associate Professor and Chief Engineer, Bergen Community College) produced this arrangement to meet the particular needs of this school. A standard or universal "off-the-shelf" laboratory package may satisfy the general group of schools, but many educators do sacrifice their creative teaching ability because of limited facilities.

ABOUT THE AUTHOR: Francis H. Yonker is a Professional Engineer and Associate Professor and Chief Engineer at Bergen Community College, Paramus, New Jersey.

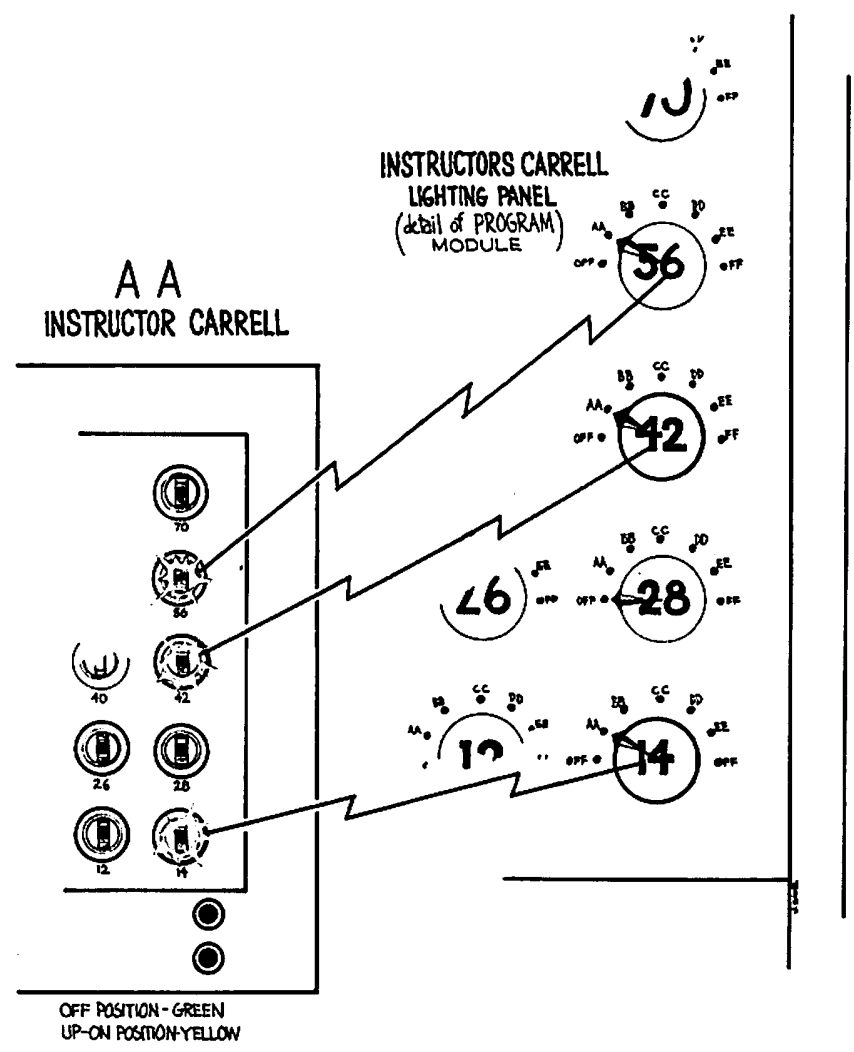

FIGURE 6 - LIGHTING the INSTRUCTORS SWITCHES 